\title{
MENDETEKSI SECARA OTOMATIS OBJEK GERAKAN BERDASARKAN GAUSSIAN MIXTURE MODEL MENGGUNAKAN APLIKASI MATLAB
}

\author{
Aldina Syahfaridzah, Adelia Kartika Panggabean, Nabila Ayu Ardiningsih \\ Fakultas Teknik \& Komputer, \\ Universitas Harapan Medan, Medan, Indonesia \\ syahfaridzahaldina@gmail.com, adeliapanggabean@gmail.com, nabilaayuardi19@gmail.com
}

\begin{abstract}
Automatically detects moving objects on a pedestrian video, each object will be detected by counting objects that appear at the beginning of the video based on a number. In detecting this object, the model used is the Gaussian Mixture Model whose performance is very effective if applied to any area that occurs in an object motion detected in the video. In this study, the Gaussian Mixture Model is used to model the background colors of each pixel. To facilitate the detection of this object, the Matlab 2016 application is also used, this application helps facilitate detection based on the size that will be adjusted according to the object to be detected.
\end{abstract}

Keywords: Detecting Moving Objects, Gaussian Mixture Model, Matlab 2016 Application.

merupakan salah satu Model Statistik yang sangat

\section{PENDAHULUAN}

Pada era globalisasi saat ini, perkembangan teknologi terjadi sangat pesat terutama dibidang Multimedia, dimana masyarakat dituntut untuk mampu mengikuti perkembangan dari teknologi yang ada. Dengan memanfaatkan komputer untuk menggabungkan teks, video, audio, dengan menggunakan tool yang memungkinkan pemakai berinteraksi, berkomunikasi dan berkreasi (Hofstetter, 2001 isi mendeley). Teknologi sekarang menjadi kebutuhan dan dapat memberikan kemudahan pada penggunanya.

Dalam mendeteksi sebuah objek menggunakan algoritma pengurangan latar belakang yang bertujuan untuk mengetahui berapa banyak objek yang terdeteksi dari suatu video dapat dilakukan secara otomatis dengan menggunakan Gaussian Mixture Model dan Aplikasi Matlab dimana gerakan tersebut secara otomatis juga akan bergerak secara Slow Motion.

Gaussian Mixture Model adalah komponen fungsi Gaussian dalam menghasilkan Multi-Model Density yang terdiri dari threshold yang berdeda, dimana Model ini merupakan sebuah tipe Density Model. (Amaluddin, Muslim, \& Naba, 2015) Menurut Stauffer dan Grimson, Gaussian Mixture Model populer dan paling sering digunakan pada kasus Adaptive Background Substraction di dalam video yang dapat beradaptasi dengan perubahan Background yang terjadi. (Parinduri, 2018)

Aplikasi Matlab adalah bahasa pemrograman tingkat tinggi yang dapat digunakan untuk melakukan pengembangan algoritma, membuat aplikasi ataupun model dan dikhususkan untuk mengolah visualisasi, pemrograman dan komputasi numerik. Aplikasi matlab ini juga merupakan aplikasi yang dikembangkan oleh MathWorks.

Penelitian ini diambil dari kasus yang terdapat di Mathwork dan menguji coba nya dengan menggunakan objek yang berbeda dengan objek yang digunakan pada kasus tersebut atau pada kasus tersebut hanya menggantikan objek yang ada, yang pada pembuatan kasus ini bertujuan untuk mendapatkan pemahaman yang lebih dari contoh pada kasus sebelumnya dan m mendapatkan hasil yang lebih dari contoh pada kasus sebelumnya dan mendapatkan hasil yang lebih dimengerti.

\section{KAJIAN LITERATUR}

Pada penelitian ini menggunakan indikator manfaat dari Gaussian Mixture Model, yang digunakan untuk mendeskripsikan piksel dan background. 
Hasil adaptasi dievaluasi dengan proses Standard Deviation, Weight, dan Means. Dimana semakin kuat penghalusan yang terjadi pada citra berarti menandakan semakin lebar distribusi kernel gaussian dan semakin besar nilai standar deviasi. Model ini juga menjadi suatu algoritma yang berfungsi dalam memodelkan distributor gaussian dengan berparameter variance dan mean. Variance merupakan ukuran dari pembesaran nilai pada set data, sedangkan Mean merupakan titik pusat dari distribusi gaussian.

Untuk suatu set data Gaussian Mixture Model dapat memodelkannya lebih dari satu Gaussian dan dapat memodelkan set data yang ada menjadi sebuah fungsi probabilistik, hal tersebut merupakan salah satu kelebihan dari Gaussian Mixture Model. Gaussian Mixture Model adalah komponen fungsi Gaussian dalam menghasilkan Multi-Model Density yang terdiri dari threshold yang berdeda, dimana Gaussian Mixture Model ini merupakan sebuah tipe Density Model. Gaussian Mixture Model berhubungan dengan suatu piksel, setiap piksel mempunyai Gaussian Mixture Model nya masingmasing dan warna piksel yang didapat dari suatu inputan yang dihasilkan dari data yang telah dioalah.

Gaussian Mixture Model ini adalah salah satu bagian dari metode Background Subtration, yang dimana model ini mampu menerima multimodal Background misalnya objek yang bergerak secara lambat, menghapus dan memperkenalkan objek dari suatu latar. Model-Model Gaussian Mixture Model terbentuk dalam data warna piksel berdasarkan dari waktu, maka Gaussian Mixture Model membentuk dua komponen utama, ialah Model Background dan Model foreground.

Dengan nilai Threshold dari Background yang sudah ditentukan, Dimana Model Background adalah Model yang mencerminkan suatu latar dari area yang diamati dan Model Foreground adalah Model yang mencerminkan suatu objek dari area yang diamati. Berikut adalah contoh Model Background dan Foreground.
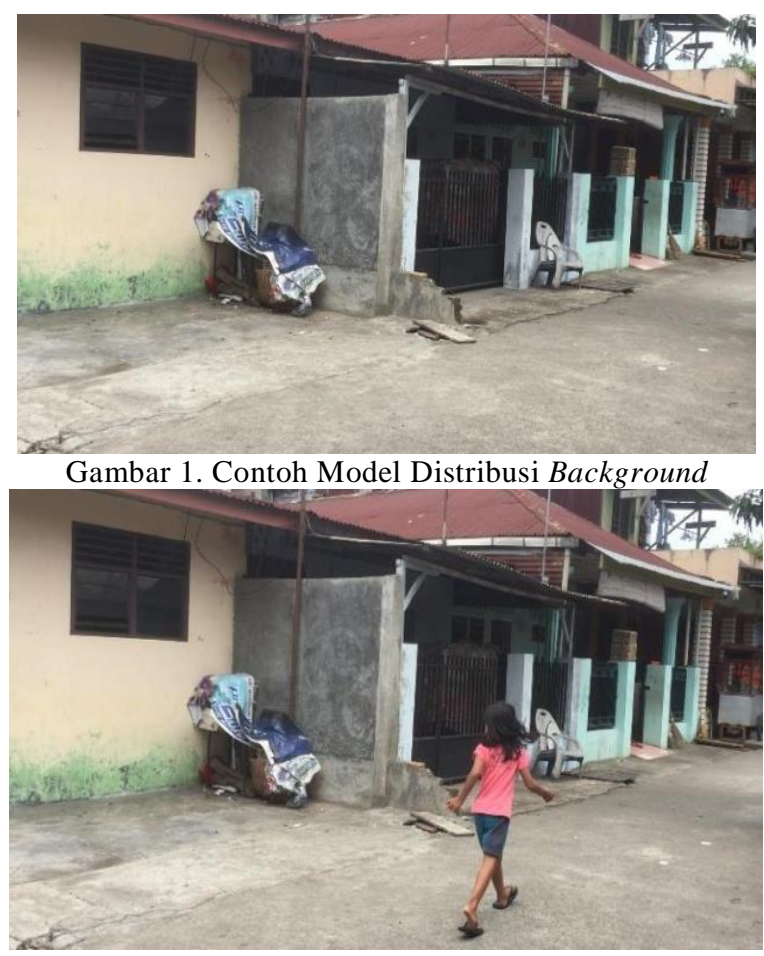

Gambar 2. Contoh Model Distribusi Foreground

Pada tahapan pemilihan distribusi Background digunakan rumus :

$$
B=\operatorname{argmin}_{b}\left(\sum_{k=1}^{b} w_{k}>T\right)
$$

Keterangan :

$\mathrm{T}=$ Batas Skala

\section{METODE PENELITIAN}

Penelitian ini dilakukan dengan menggunakan Model Gaussian Mixture Model, dimana manfaat dari Model Gaussian Mixture Model ini sebagai indikator dalam penelitian yang telah dibuat. Responden pada penelitian ini adalah semua objek bisa berupa manusia, benda dan objek lainnya yang bergerak dan terdeteksi dari video yang akan diteliti dengan menggunakan aplikasi matlab sebagai alat yang akan digunakan dalam penelitian dari objek yang berbeda dengan objek yang ada yang terdapat pada kasus sebenarnya. Dengan menggunakan tahapan Motion Detection sebuah citra yang tertangkap di dalam video akan digunakan sebagai bahan utama dalam suatu proses analisa.

Dalam melakukan penelitian ini selain berpedoman dengan kasus sebelumnya, penulis juga melakukan 
metode untuk menambah wawasan yang akan dibuat dalam penelitian dimana tahapan tersebut merupakan tahapan teknik pengumpulan data. Pada tahapan ini dilakukan dengan cara mengumpulkan dan menyempurnakan data-data yang dibutuhkan dalam penelitian yaitu dengan menggunakan dokumen tertulis dalam berbagai buku-buku dan juga referensi yang berkaitan dengan materi yang dibahas dalam penelitian.

\section{HASIL DAN PEMBAHASAN}

Pada tahapan ini dilakukan penyajian tentang hasil dari data-data uji coba yang telah dilakukan pendeteksian dan pelacakan dari video yang meliputi beberapa objek dan dalam tahapan ini akan dijelaskan secara singkat tentang beberapa tahapan pengujian dalam sistem. Pada tahapan kasus ini video yang akan dideteksi dan dilacak menggunakan format (*.mp4), dan akan lebih baik jika video yang digunakan tersebut memakai format (*.avi).

\section{A. Filter Gaussian Mixture Model}

Hasil yang diperoleh dari uji coba atau penelitian ini menunjukkan bahwa model ini adalah suatu metode yang memperlihatkan perubahan nilai piksel yang stabil terhadap gerakan yang berulangulang atau terhadap perubahan pencahayaan dari video yang di uji. Gaussian Mixture Model tidak selalu mendeteksi dengan akurat, Gaussian Mixture Model dapat mendeteksi atau dapat melakukan pelacakan pada semua objek yang bergerak.

Maka, jika hanya ada satu objek yang ingin di perhitungkan harus dipastikan video yang akan diuji tidak terdapat objek yang bergerak lainnya sehingga pada tahapan uji coba objek yang terdeteksi sesuai dengan target utama.

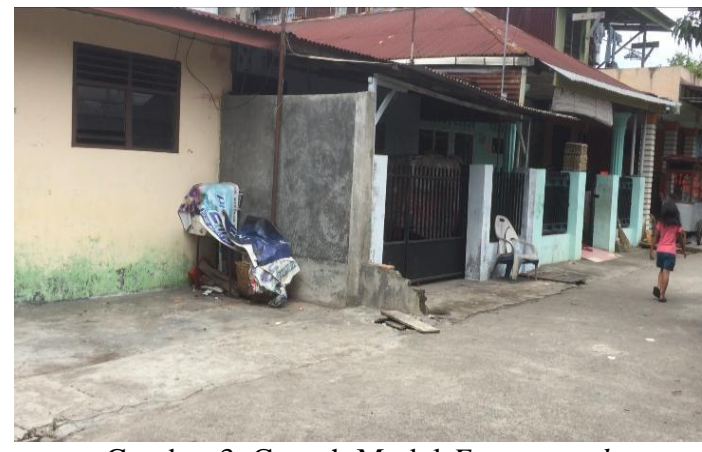

Gambar 3. Contoh Model Foreground
Dalam contoh model foreground ini terlihat ada satu objek yang akan di deteksi. Jika bentuk Foreground Mask yang terdeteksi dalam Gaussian Mixture Model terlihat lebih bagus atau lebih sempurna maka sedikit noise yang terjadi pada tahapan uji coba ini dikarenakan hasil dari video yang diuji tidak terdapat gangguan atau bayanganbayangan dari objek lain yang bergerak, Gaussian Mixture Model tidak selalu dapat beradaptasi dengan baik pada perubahan Foreground atau lingkungan seperti gangguan dari bayanganbayangan pada objek yang ada.B. Hasil Segmentasi

Pada tahapan ini akan diketahui hasil dari objek yang telah diteliti, pada tahapan ini Gaussian Mixture Model dan Aplikasi Matlab akan mendeteksi atau melacak video dengan memperhitungkan jumlah objek yang bergerak di dalam video yang diuji. Berikut merupakan contoh hasil dari segmentasi yang dilakukan dengan beberapa objek.

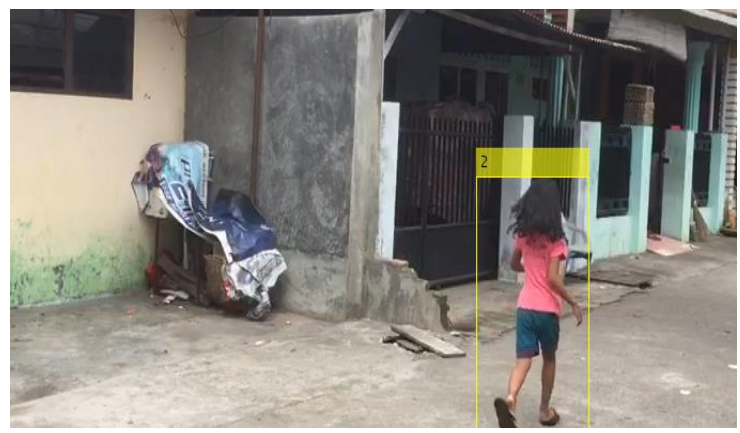

Gambar 5. Hasil Segmentasi Pada Objek 1

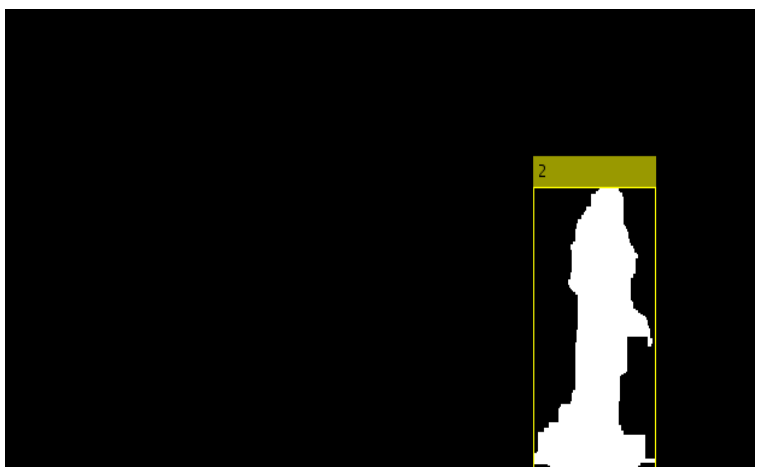

Gambar 6. Hasil Segmentasi Mask Pada Objek 1 


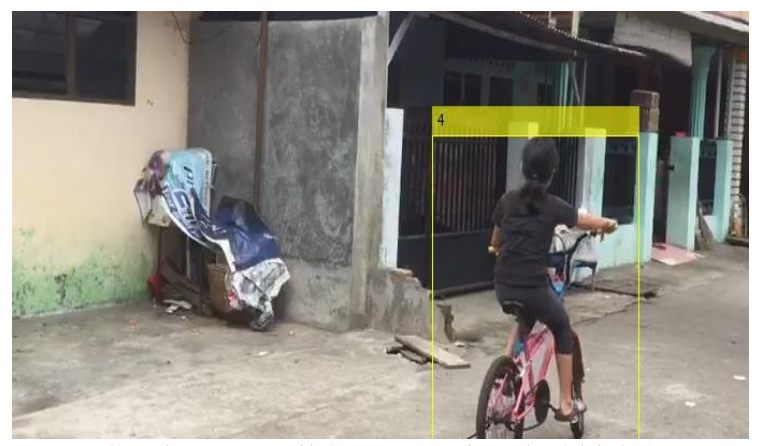

Gambar 7. Hasil Segmentasi Pada Objek 2

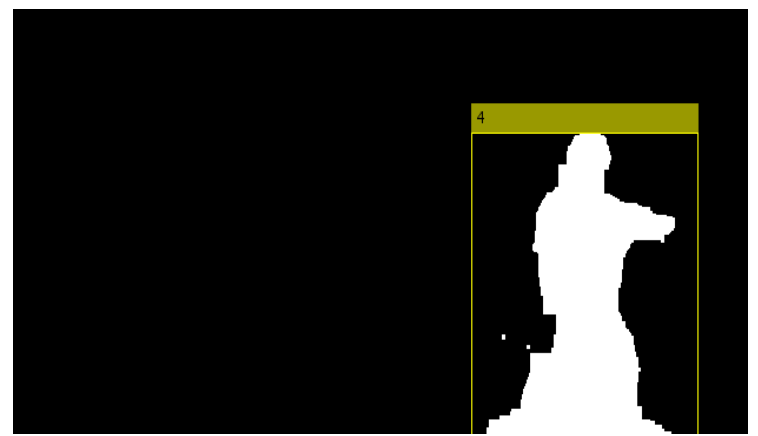

Gambar 8. Hasil Segmentasi Mask Pada Objek 2

Dari gambar hasil segmentasi diatas terlihat bahwa ada dua objek bergerak yang terdeteksi atau terlacak dengan menggunakan algoritma pengurangan latar belakang dan berdasarkan oleh atau melalui Gaussian Mixture Model dan Aplikasi Matlab, yaitu pejalan kaki dan pesepeda. Terdapat latar belakang atau bingkai yang menghitung berapa jumlah objek yang ada.

Kesalahan pada pendeteksian dan pelacakan dapat diminimalisir menggunakan video dengan objek gerak yang lebih teratur dan lebih kompleks. Pada pendeteksian ini juga menggunakan operasi morfologi, yang bertujuan untuk mengurangi gerakan-gerakan yang sepertinya tidak perlu untuk dideteksi atau disegmentasi dan memperkecil bentuk dimensi pada objek agar sesuai ukurannya meskipun hasil segmentasi tidak menghilangkan noise sepenuhnya namun ini sedikit membantu membuat hasil segmentasi yang lebih sempurna.

\section{KESIMPULAN}

Tujuan dari penelitian ini adalah untuk mendeteksi atau melakukan pelacakan dari sebuah objek menggunakan algoritma pengurangan latar belakang yang bertujuan untuk mengetahui berapa banyak objek yang terdeteksi dari suatu video yang dapat dilakukan secara otomatis dengan menggunakan Gaussian Mixture Model dan Aplikasi Matlab. Penelitian ini diambil dari kasus yang terdapat di Mathwork dan menguji coba nya dengan menggunakan objek yang berbeda dengan objek yang digunakan pada kasus tersebut. Setiap objek bergerak yang terdeteksi akan dihitung jumlahnya menggunakan bingkai. Dari gambar hasil segmentasi diatas terlihat bahwa ada dua objek bergerak yang terdeteksi atau terlacak dengan menggunakan algoritma pengurangan latar belakang dan berdasarkan melalui Gaussian Mixture Model dan Aplikasi Matlab, yaitu pejalan kaki dan pesepeda.

Saran bagi penelitian selanjutnya adalah diharapkan rumus penjabaran pada Gaussian Mixture Model lebih diperjelas, materi pendeteksian objek bergerak yang dilakukan selanjutmya menggunakan jenis video yang berbeda dan diperjelas dengan kata-kata yang mudah dimengerti banyak kalangan.

\section{DAFTAR PUSTAKA}

[1]. Airlangga, U. (2019). PENGARUH PENERIMAAN SISTEM PEMBAYARAN E-CASH DENGAN MENGGUNAKAN TAM ( TECHNOLOGY ACCEPTANCE MODEL ) TERHADAP INTENSITAS TRANSAKSI NON TUNAI Victor Jonathan Mahubessy. 3(2), 160-165.

[2]. Amaluddin, F., Muslim, M., \& Naba, A. (2015). Klasifikasi Kendaraan Menggunakan Gaussian Mixture Model (GMM) Dan Fuzzy Cluster K Means (FCM). Jurnal EECCIS, 9(1), pp.19-24.

[3]. Ansari, R. D., Purnama, B., Si, S., \& Sthevanie, F. (2014). Penerapan dan Analisis Sistem Penghitungan Orang Menggunakan Adaptive Gaussian Mixture Model dan Local Binary Pattern Implementation and Analysis of People Counting System Using Adaptive Gaussian Mixture Model and Local Binary Pattern. EProceeding of Engineering, 2(2), 6008-6015.

[4]. Himawan, F., \& Al Fatta, H. (2012). Pembuatan Video Klip "Terbang" Oleh "Flourescent Band" Dengan Menggunakan Teknik Stop Motion. Data 
Manajemen Dan Teknologi Informasi (DASI), 13(4), 17.

[5]. Munawaroh, Y. F., \& Salamah, I. (2018). Analisa Perbandingan Algoritma Histogram of Oriented Gradient ( HOG ) dan Gaussian Mixture Model ( GMM ) Dalam Mendeteksi Manusia. 251-255.

[6]. Parinduri, I. (2018). Model dan Simulasi Rangkaian RLC Menggunakan Aplikasi Matlab Metode Simulink.

[7]. Journal of Science and Social Research, 1(1), 42-47.

[8]. Prakoso, D. H., Purnama, B., \& Sthevanie, F. (2015). Penghitungan Orang dengan Metode Gaussian Mixture Model dan Human Presence Map Studi Kasus : Penghitungan Orang di dalam Kelas. 2(1), 1562-1573.

[9]. Putra, D. K., Iwut, I., \& Atmaja, R. D. (2017). Simulasi Dan Analisis Speaker Recognition Menggunakan Metode Mel Frequency Cepstrum Coefficient (mfcc) Dan Gaussian Mixture Model (gmm). EProceedings of Engineering, 4(2), 17661772. Retrieved from http://libraryeproceeding.telkomuniversity.ac.id/ind ex.php/engineering/article/view/487/460 